\title{
Non-syndromic oral clefts: a glimpse on environmental risk factors- a mini-review
}

Volume 6 Issue $3-2017$

Keywords: oral clefts, cleft lip/ palate, environmental risk factors, smoking, nutrition, pregnancy

\section{Introduction}

Worldwide, oral clefts (OC) are considered among the most common birth defects with an estimated rate of 1 per 500-1000 live births. ${ }^{1}$ Disparities in prevalence of OC are largely related to ethnic, geographic and socioeconomic variations such that the highest rates have been reported among Asians and Native American whereas Africa-based populations are at the lowest risk to develop such defects. ${ }^{2}$ Typical orofacial clefts which comprise cleft lip with or without cleft palate $(\mathrm{CL} / \mathrm{P})$ and isolated cleft palate $(\mathrm{CP})$ are mostly non-syndromic and occur as isolated defects. Only $30 \%$ are associated with other structural or systemic defects as a part of a recognized syndrome. ${ }^{2,3}$

Children with $\mathrm{OC}$ tend to suffer from feeding problems and hence delayed growth, difficulties in speech, hearing disorders and physical disfigurement. This in turn leads to low self-esteem, social isolation and impairs a child's ability to integrate into the surrounding environment., ${ }^{4,5}$ In low income countries, where resources and multidisciplinary cleft care including surgical repair, dental treatment, speech therapy and psychological support are lacking, infant mortality has become common due to poor nutrition and high risk to acquire infectious diseases. ${ }^{6}$ Having a child with oral cleft substantially imposes negative psychosocial and financial burdens for the affected family. ${ }^{7}$

\section{Etiology}

Though there is no global agreement on the exact etiology of OC yet it is well known that a complex interplay between both genetic factors and environmental teratogens contributes to their development. Understanding the developmental disturbances associated with $\mathrm{OC}$ and identifying the modifiable environmental factors offer an excellent opportunity for devising programs for primary prevention of these deformities.

Multiple environmental exposures contributing to $\mathrm{OC}$ have been extensively researched including maternal obesity, stress, diabetes and tobacco use as well as alcohol or drugs consumption. Though several studies have lent support to the hypothesis that maternal tobacco use and exposure to passive smoking during the first trimester are positively associated with $\mathrm{CL} / \mathrm{P}^{9,10}$ however a recent meta-analysis failed to confirm a dosage response relationship. (11) As revealed in many studies, the risk of OC is also high among expectant mothers using anticonvulsants such as valproic acid and phenytoin in early gestation. ${ }^{12,13}$

Despite the existing controversies regarding the relationship between maternal pre-pregnancy weight and development of oral clefts, it has been lately confirmed that obese women are at higher

\author{
Reham Abou El Fadl \\ Lecturer of Pediatric Dentistry and Dental Public Health, Ain \\ Shams University, Egypt
}

Correspondence: Reham Abou El fadl, PhD Pediatric Dentistry, MPH, BSC, Heliopolis, Cairo, Egypt, Email reham.k.abouelfadi@gmail.com

Received: January 27, 2017| Published: February 24, 2017 risk to deliver children with $\mathrm{CL} / \mathrm{P} .{ }^{14}$ Moreover, it was suggested that both overweight and underweight interfere with the process of palatal development. ${ }^{15}$ This could be linked to maternal nutritional deficiencies and imbalanced dietary patterns during pregnancy which have been strongly associated with the development of OC. In many studies, it has been reiterated that mothers whose dietary intake contains low levels of essential micronutrients present in liver per se such as vitamin B6 and B12, zinc and folate are at higher risk to have infants with OC..$^{16-19}$ It has been claimed that using folate supplements alone reduces the risk of oral clefts (20) Nevertheless, recently it was revealed that maternal use of multivitamins containing folic acid rather than folic acid-only when combined with proper dietary patterns rich in fruits, vegetables, whole grains, low-fat dairy food, nuts and liver has a stronger impact on decreasing the risk of OC thereby implying that several micronutrients have a role in that. ${ }^{19-22}$ In obese women having pre-pregnancy diabetes, it was also found that the synergistic effect of hyperglycemia coupled with obesity could increase the odds of cleft lip with cleft palate per se. ${ }^{23}$

\section{Implications}

Public health strategies need to be set to promote smoking cessation programs among women with childbearing potential and ensure their access to preconception orientation and awareness sessions on plausible risk factors of oral clefts and importance of adequate dietary patterns as a routine part of prenatal care. These strategies should primarily focus on vulnerable groups including poor and uneducated women to ensure health equity.

Genetic counseling should be conducted for families at high risk of having children with oral clefts.

Health professionals should be well trained to educate pregnant women about various risk factors of $\mathrm{OC}$ and to provide parents having a child with cleft with postnatal psychological assistance and adequate information on proper feeding practices and required rehabilitative treatment. 


\section{Acknowledgments}

None.

\section{Conflicts of interest}

Author declares there are no conflicts of interest.

\section{Funding}

None.

\section{References}

1. World Health Organization. Oral health Fact sheet N`318, April. 2012.

2. Mossey PA, Little J, Munger RG, et al. Cleft lip and palate. Lancet 2009;374(9703):1773-1785.

3. Calzolari E, Pierini A, Astolfi G, et al. Associated anomalies in multimalformed infants with cleft lip and palate: an epidemiologic study of nearly 6 million births in 23 EUROCAT registries. Am J Med Genet A. 2007;143(6):528-537.

4. Yunusa MA, Obembe A. Prevalence of psychiatric morbidity using GHQ-28 among cleft lip patients in Sokoto. Ann Afr Med. 2013;12(2):135-139.

5. Fadeyibi IO, Coker OA, Zacchariah MP, et al. Psychosocial effects of cleft lip and palate on Nigerians: the Ikeja-Lagos experience. $J$ Plast Surg Hand Surg. 2012;46(1):13-18.

6. Conway JC, Taub P, Kling R, et al. Ten-year experience of more than 35,000 orofacial clefts in Africa. BMC Pediatr. 2015;15:18.

7. Wehby G, Cassell CH. The impact of orofacial clefts on quality of life and healthcare use and costs. Oral Dis. 2010;16(1):3-10.

8. Dixon MJ, Marazita ML, Beaty $\mathrm{TH}$, et al. Cleft lip and palate: understanding genetic and environmental influences. Nat Rev Genet. 2011;12(3):167-178.

9. Shi M, Christensen K, Weinberg CR, et al. Orofacial cleft risk is increased with maternal smoking and specific detoxification-gene variants. Am J Hum Genet. 2007;80(1):76-90.

10. Little J, Cardy A, Munger RG. Tobacco smoking and oral clefts: a metaanalysis. Bull World Health Organ . 2004;82(3):213-218.

11. Xuan Z, Zhongpeng Y, Yanjun G, et al. Maternal active smoking and risk of oral clefts: a meta-analysis. Oral Surg Oral Med Oral Pathol Oral Radiol. 2006;122(6):680-690.
12. Werler MM, Ahrens KA, Bosco JL, et al. Use of Antiepileptic Medications in Pregnancy in Relation to Risks of Birth Defects. Ann Epidemiol . 2011;21(11):842-850.

13. Puhó EH, Szunyogh M, Métneki J, et al. Drug treatment during pregnancy and isolated orofacial clefts in Hungary. Cleft Palate Craniofac J. 2007;44(2):194-202.

14. Blanco R, Colombo A, Suazo J. Maternal obesity is a risk factor for orofacial clefts: a meta-analysis. $\mathrm{Br} J$ Oral Maxillofac Surg. 2015;53(8):699-704.

15. Kutbi H, Wehby GL, Moreno Uribe LM, et al. Maternal underweight and obesity and risk of orofacial clefts in a large international consortium of population-based studies. Int J Epidemiol. 2016.

16. Tamura T, Munger RG, Corcoran C, et al. Plasma zinc concentrations of mothers and the risk of nonsyndromic oral clefts in their children: a case-control study in the Philippines. Birth Defects Res A Clin Mol Teratol . 2005;73(9): 612-616.

17. Munger RG, Sauberlich HE, Corcoran C, et al. Maternal vitamin B-6 and folate status and risk of oral cleft birth defects in the Philippines. Birth Defects Res A Clin Mol Teratol. 2004; 70(7): 464-471.

18. van Rooij IA, Swinkels DW, Blom HJ, et al. Vitamin and homocysteine status of mothers and infants and the risk of nonsyndromic orofacial clefts. Am J Obs Gynecol. 2003;189(4):1155-1160.

19. McKinney CM, Chowchuen B, Pitiphat W, et al. Micronutrients and oral clefts. A case Control study. J Dent Res . 2013;92(12):1089-1094.

20. Wilcox AJ, Lie RT, Solvoll K, et al. Folic acid supplements and risk of facial clefts: national population based case-control study BMJ. 2007;334(7591):464.

21. La H, Munger RG, Wengreen $H$, et al. Maternal multivitamin use, DASH dietary pattern, and risk of oral clefts in Utah. The 12th International Congress on Cleft Lip/Palate and Related Craniofacial Anomalies. Orlando, FL, USA. 2013.

22. Gildestad T, Bjørge T, Vollset SE, et al. Folic acid supplements and risk for oral clefts in the newborn: a population-based study. Br J Nutr. 2015;114(9):1456-1463.

23. Parker SE, Werler MM, Shaw GM, et al. and the National Birth Defects Prevention Study. Dietary Glycemic Index and the Risk of Birth Defects. Am J Epidemiol . 2012;176(12):1110-1120. 